\title{
Educação para \\ o Reconhecimento do Outro: \\ um Desafio a Partir de Lima Vaz
}

\author{
Anderson Luiz Tedesco ${ }^{1}$ \\ Roque Strieder ${ }^{2}$ \\ Clenio Lago ${ }^{3}$
}

\begin{abstract}
Resumo
0 artigo é uma discussão inspirada nas concepções filosóficas de Henrique Cláudio de Lima Vaz. Trata-se de um estudo de caráter bibliográfico, com o objetivo de constituir uma reflexão ética na educação contemporânea. Diante da fragilização da intersubjetividade, construída no decorrer da modernidade, resultam algumas possibilidades educativas capazes de reconstruir o reencontro entre seres humanos. Conclui-se que o ser humano, ao conviver em comunidade, interage no terreno da educação como caminho intersubjetivo de conhecimento de si e de transformação de si na relação de reconhecimento do Eu-Tu ou Eu-Humanidade.
\end{abstract}

Palavras-chave: Lima Vaz. Intersubjetividade. Educação.

1 Doutorando em Filosofia - PUCPR, mestre em Educação pela Unoesc. Linha de Pesquisa Processos Educativos. andersonunoesc@ hotmail.com

2 Doutor em Educação pela Universidade Metodista de Piracicaba - Unimep/SP; professor do Programa de Mestrado em Educação da Unoesc. Temáticas de estudo: Educação e Formação Humana. Ética e Educação. Grupo de Pesquisa: Formação Docente e Práticas de Ensino. roque. strieder@unoesc.edu.br

3 Doutor em Educação - PUCRS (2011). Pesquisador do Programa de Pós-Graduação em Educação da Unoesc. Mestrado em Educação. cleniolago@yahoo.com.br 


\section{EDUCATION FOR OTHER RECOGNITION:}

A Challenge From Lima Vaz

\section{Abstract}

The article is a discussion inspired by the philosophical conceptions of Henrique Claudio de Lima Vaz. it is a bibliographical study, in order to constitute an ethical reflection on contemporary education. Given the fragility of inter-subjectivity, built in the course of modernity, result some educational possibilities able to reconstruct the reunion between humans. It is concluded that the human being, to live in community interacts in the field of education as inter-subjective way of self-knowledge and transformation of the self in recognition of I-you or I-Humanity.

Keywords: Lima Vaz. Intersubjectivity. Education.

Recebido em: 11/11/2016

Aceito em: 15/7/2017 


\section{Construções Filosóficas em Lima Vaz}

O dia 24/8/1921 lembra, entre outros fatos, o nascimento de um dos maiores filósofos do Brasil - Henrique Cláudio de Lima Vaz - na cidade de Ouro Preto/MG. Vaz faleceu em 23/5/2002 em Belo Horizonte. Aos estudiosos da filosofia deixou um legado inestimável, com muito ainda a ser desvelado.

Neste artigo objetiva-se refletir, com base nas concepções de Vaz, acerca da educação como Paideia ética na contemporaneidade, articulando a educação como processo intersubjetivo desde a sua herança filosófica. No segundo momento e, diante da fragilização da intersubjetividade, construída no decorrer da modernidade, propor, apoiados em Vaz, reflexões para visualizar possibilidades educativas capazes de reconstruir o reencontro dos seres humanos como processo intersubjetivo, no âmbito da linguagem.

A formação humana de Vaz, iniciada em 1938, tem como referência a congregação religiosa da Companhia de Jesus. Vaz iniciou os estudos de Filosofia em Nova Friburgo/RJ, tendo reconhecida sua aptidão para reflexões filosóficas. Em 1945 começa, na Pontifícia Universidade Gregoriana de Roma, os estudos de teologia. Lá escreveu sua dissertação intitulada "O problema da beatitude em Aristotéles e Santo Tomás”. Em 1948 foi ordenado sacerdote e, em 1952, concluiu os estudos de doutoramento em Filosofia, com a tese "De dialectica et contemplatione in Platonis dialogis" (A dialética e a intuição nos diálogos platônicos da maturidade).

Vaz retorna ao Brasil e é convidado a lecionar na Faculdade da Companhia de Jesus, em Nova Friburgo, no período de 1953 a 1963. Com passagem também por São Paulo, retorna a Belo Horizonte, falecendo no ano de 2002. Teve grande contribuição no Departamento de Filosofia e Ciências Humanas da UFMG, sendo reconhecido como Professor Emérito no ano de 2001.

Sobre as reflexões filosóficas de Vaz, Sampaio (2001) afirma que elas passam por três momentos distintos.

Primeiro, o contato de Vaz com o universo filosófico no decorrer de sua formação acadêmica, período dedicado aos estudos da ontologia clássica a partir das obras de Platão, Aristóteles e Tomás de Aquino. Esses estudos seguiram 
"numa perspectiva ontológica e metafísica, investigando o problema da possibilidade de uma ciência do ser e de uma justificação do Absoluto portador do predicado de transcendente" (SAMPAIO, 2001, p. 9).

O segundo, dedicado aos estudos de Galileu, Descartes, Espinoza e Kant, contempla as construções reflexivas acerca da ciência moderna. De acordo com Sampaio (2001, p. 10), não se pode esquecer a influência do "jesuíta belga Joseph Maréchal, que procurava uma síntese entre o tomismo e o método transcendental". Diante desse problema, as reflexões de Lima Vaz apresentam como diferencial a criação de duas novas racionalidades para além da teleológica do pensamento clássico: a nomotética e a hipotética-dedutiva.

Para Sampaio (2006, p. 92), "os pressupostos epistemológicos da passagem do horizonte clássico (universalidade nomotética) para o horizonte da modernidade (universalidade hipotético-dedutivo) foi a revolução científica". Para Vaz: A universalidade nomotética ${ }^{4}$ é aquela que tem como fundamento uma ordem do mundo que se supõe manifesta e na qual o nómos ou lei da cidade é o modo de vida do homem que reflete a ordem cósmica contemplada pela razão. A universalidade hipotética, ao invés, é aquela cujo fundamento permanece oculto e requer uma explicação a título de hipótese inicial não verificada empiricamente e que deve ser confirmada dedutivamente pelas suas consequências. [...] essa passagem constitui o desafio maior da reflexão política contemporânea (2004, p. 147).

As constatações de Vaz sugerem que a racionalidade nomotética articula-se com a política e a ética para constituir o ethos na polis e, com o advento da modernidade, sob a égide da tecnociência, "a política constituiu-se como esfera autônoma e independente da normativa ética" (SAMPAIO, 2006).

No terceiro momento destacam-se estudos e compreensão do pensamento hegeliano dedicando-se à racionalidade dialética que "transcreve a universalidade nomotética na moderna metafísica da subjetividade" (SAMPAIO, 2001,

\footnotetext{
4 "Nomotética se diz propriamente da arte de legislar. Nomothétes é o legislador. Aqui aplicamos analogicamente o termo a uma ordem objetiva que se põe como lei e é, como tal, apreendida pela razão" (VAZ, 2004, p. 146).
} 
p. 10). Conjuntamente, Vaz estudava o pensamento de Marx como auxiliador na interpretação do pensamento hegeliano. Nesse momento as construções reflexivas da filosofia vaziana concentram-se na crise da modernidade, exigindo um retorno à tradição clássica, uma vez que:

O exercício do ato de filosofar é sempre uma "rememoração" [...] e uma atenção" que podemos chamar conceptualizante, ou seja, pensada, refletida e discursivamente explicada, à realidade. Duas dimensões que nascem da mesma origem do ato de filosofar [...] e que definem o espaço espiritual onde a Filosofia tem a sua morada e onde vive. Filosofa é anámensis - recordação - e é noésis - pensamento" (VAZ, 1991, p. 685).

Este é um reencontro com a ideia de logos, posto que, segundo Vaz (1991, p. 687), é necessário recuperar "a ideia de sistema no sentido de articulação ordenada no pensamento, sem a qual não há leitura coerente da realidade, e a filosofia se esvai em gratuitos jogos de linguagem". Conforme Sampaio (2006, p. 229), "o método da dialética é o único que procede, por meio da destruição das hipóteses, a caminho do autêntico princípio, a fim de tornar seguros os seus resultados". É nesse momento que ocorre "a elaboração da sua Antropologia Filosófica, e o tema da intersubjetividade encontra sua sistematização mais acabada" (SAMPAIO, 2001, p. 11).

A consistência conceitual e argumentativa do pensamento de Vaz resulta do exercício de profunda reflexão e busca de melhor compreensão unitária (ontológica) do que é o ser humano. Assim, compreender a concepção de ser humano, no pensamento de Vaz, é um desafio complexo e exigente para conhecer e entender suas concepções, expostas de maneira metódica, sistemática e dialética. Essas concepções constituem um sistema antropológico-filosófico de estruturas organizadas em três fases. ${ }^{5}$

5 O sistema filosófico de Vaz “[...] caracteriza-se por uma estrutura triádica e tem como pilares sua antropologia (livros Antropologia filosófica I e II), sua ética (livros Escritos de filosofia IV e V) e sua metafísica (Escritos de filosofia VII - Raízes da Modernidade)" (SAMPAIO, 2011, p. 14). 
A primeira fase enfatiza a pré-compreensão, um contexto histórico-cultural da construção das formas simbólicas e manifestações religiosas, possibilitando a existência do ser humano. A segunda destaca a compreensão-explicativa, caracterizada pela formalização das ciências buscando refletir e explicar o ser humano. E, como terceira, a compreensão-filosófica (ou transcendental) caracterizada por um exercício dialético de compreensão da constituição do ser humano em seu sentido ontológico, algo que transcende a lógica das ciências padronizadas (VAZ, 2006).

Essas três compreensões, como estruturas e categorias essenciais, fundamentando os estudos acerca do ser humano, não são fechadas em si mesmas. Elas se organizam em novas categorias basilares para reconstituir, com profundidade e complexidade, a ideia de pessoa em nível ontológico com reflexões antropológicas.

De acordo com Vaz (2006, p. 154), as disposições dessas categorias ontológicas são: “a) estrutura somática (do corpo próprio); b) estrutura psíquica (do psiquismo); e c) estrutura espiritual (do espírito)". Como categorias ontológicas elas se associam ao conceito de relação que, consoante Vaz (2006, p. 154), envolve: “a) uma relação com o mundo (a objetividade); b) uma relação com o Outro (a intersubjetividade); e c) uma relação com o Absoluto (a Transcendência)". A conjugação dessas categorias leva à unidade entre as estruturas e as relações, ou seja: a) unidade como unificação (categoria da realização) e b) unidade como ser-uno (categoria da essência).

Feitas essas recuperações desde a proposta filosófica de Lima Vaz e seguindo sua linha de desenvolvimento epistemológico, sua forma de pensar inspirou a construção dos procedimentos metodológicos dessa reflexão, tendo como objetivo refletir a despeito da possibilidade de construção de uma educação ética nos contextos educativos contemporâneos, haja vista toda desconstrução histórica e linear dos processos de humanização do Ser Humano. Nossa problemática, nessa discussão, fica expressa como: Diante da fragilização da intersubjetividade, construída no decorrer da modernidade, resultam algumas possibilidades educativas capazes de reconstruir o reencontro entre seres humanos? Por isso, pretende-se entender possíveis contribuições para o processo 
educativo na complexa e obscura contemporaneidade, considerando o incômodo do historicismo que, por ousar eliminar a dimensão deontológica da ética, caiu no relativismo. Este, porém, obrigou a repensar o deontológico em meio aos desafios da historicidade e da realidade em produção, uma vez que o lugar da ética é o entre-ser do ser em acontecimento.

\section{Educação e Suas Entradas na Contemporaneidade}

Consideramos relevante reconhecer que, na complexa contemporaneidade, a temporalidade presente implica constante retorno a si e ao outro na intersubjetividade, uma forma de posicionar-se diante dos processos de subjetivação das identidades pessoais, olhando o não vivido no que é vivido. Nesse sentido cabe referendar Agamben (2009) e suas reflexões sobre contemporaneidade, amizade e comunidade que vem.

A contemporaneidade requer ambientes de conversação e de linguagem que permitem não somente relatar, mas ouvir experiências com identidade que, mais do que a saída fragmentária, expressam inúmeras singularidades, como jeitos diferentes de interpretar e compreender a natureza e a vida na natureza. É uma possibilidade de visualizar, como no firmamento noturno, que o brilho de uma estrela encontra-se circundada pelas trevas; trevas que resultam de um universo em expansão, no qual "as galáxias mais remotas se distanciam de nós a uma velocidade tão grande que sua luz não consegue nos alcançar. Aquilo que percebemos como o escuro do céu é essa luz que viaja velocíssima até nós e, no entanto, não pode nos alcançar" (AGAMBEN, 2010, p. 64-65). A contemporaneidade é, então, também uma oportunidade para perceber que, por entre as trevas da complexidade do ser humano, cada um externa seu brilho e sua escuridão em luminescências singulares e próprias, como negação do esforço reducionista e homogeneizador (AGAMBEN, 2010).

$\mathrm{Na}$ contemporaneidade, envolta em complexidades diversas, é importante entender que o brilho por entre as trevas é inentendível, ou seja, expressa uma educação como Paideia, tendo como premissa a fragilidade do mero adestrar, determinar e enformar. A educação para uma paideia ética se reveste 
do conversar, da simplicidade e da humildade para perceber a luz e a escuridão individual de cada ser humano, dando-se um ser, construindo-se bebendo da diversidade das demais luzes e trevas, para, então, formar sua singularidade na experiência do vivido.

\section{O Racionalismo e a Fragilização da Intersubjetividade}

O sistema filosófico proposto por Vaz tem estrutura triádica, baseado na antropologia, na ética e na metafísica, um conjunto de variáveis consideradas essenciais para refletir a concepção de ser humano nos contextos da racionalidade. As reflexões de Vaz vão à contramão da racionalidade contemporânea, cujas investigações, de cunho científico e com forte inclinação reducionista, priorizam aspectos de caráter utilitarista, pautada em resultados e produtos.

A importância das proposições de Vaz, questionando os racionalismos, encontra sustento em outras reflexões e, a título de ilustração, citamos Monod (2002), ao externar sua preocupação diante da fragilização, mesmo que negada pela ciência e atual tecnociência, imposta ao sistema de valores humanos:

As sociedades modernas aceitaram as riquezas e os poderes que a Ciência lhes oferecia. Mas não aceitaram ou vagamente se aperceberam da mensagem mais profunda da ciência: a definição de uma nova e única fonte de verdade, a exigência de uma revisão total dos fundamentos da ética, de uma ruptura radical com a tradição animista, o abandono definitivo da "antiga aliança" e a necessidade de criar uma outra. Armadas de todos os poderes, usufruindo de todas as riquezas que devem à Ciência as nossas sociedades tentam, ainda, viver e ensinar sistemas de valores, roídos já, na raiz, pela própria ciência (p. 114).

Shattuck (1998, p. 181) alerta que a priorização da ciência, aplicada aos interesses comerciais e ao poder, negligencia o fato de ter "em mãos os riscos potenciais [...] e sua responsabilidade ética". A história humana mostra fragilidades éticas e falta de prudência nas pesquisas científicas, permitindo 
a construção das bombas atômicas, as investigações no campo da genética, as propostas de terapias gênicas, entre outros eventos que também marcam a contemporaneidade fechada em ideologias que buscam o poder.

Essa fragilidade ética foi, também, manifesta pelo cardeal Ratzinger (2004), na Academia da Baviera, em debate com Habermas sobre "bases pré-políticas e morais do Estado democrático":

Parece-me evidente que a ciência como tal não pode gerar ethos, que, portanto, uma consciência ética renovada não pode surgir como produto de debates científicos. Por outro lado, é certamente também indiscutível que a alteração fundamental da imagem humana e mundial, a qual se deu a partir da evolução dos conhecimentos científicos, está essencialmente ocupada com a ruptura de velhas certezas morais (grifos nossos).

Por outro lado, a sociedade consumista e hedonista objetivou o corpo humano ao disseminar a morte da intersubjetividade em, praticamente, todos os setores sociais, inclusive nos ambientes escolares. Impôs-se a era do corpo como objeto científico, facilmente moldável conforme o gosto do indivíduo, reduzido à "gestão de si" via estetização, um novo modo de formação do ethos contemporâneo.

A obsessão de reduzir o ser humano à dimensão puramente biológica, de superfície e presentificada é resultado, segundo Vaz (2006, p. 218), do “empobrecimento da noção de virtude na Ética ${ }^{6}$ moderna e do seu quase desaparecimento no horizonte da filosofia contemporânea". Essa perda de virtude tem contribuído de maneira negativa na "descaracterização do conceito de ato espiritual".

${ }_{6}$ Para Ribeiro (2011, p. 39): "a reflexão de Lima Vaz converge para essa simples e profunda evidência de que a ética [...] é um programa pedagógico que visa educar o indivíduo e a comunidade para a vida plenamente humana. Sem educação ética [...] não há autêntica participação política, não há direitos humanos, não há constituições justas, não há predomínio do humano sobre o econômico [...] O mundo ético será não uma dádiva graciosa da natureza, mas uma lenta, dura e exigente conquista da civilização [...] sempre recomeçada e sempre ameaçada pela queda". 


\section{A Vivência Intersubjetiva: Um Ato do Espírito}

A construção do sistema filosófico vaziano fundamenta-se na compreensão do ato espiritual como "o ato pelo qual se exerce e se manifesta no homem a vida do espírito. Como tal, ele é, por excelência, o ato humano, e seu fundamento é a estrutura ontológica total do ser humano" (VAZ, 2006, p. 219). Esse ato espiritual possui propriedades fenomenológicas que podem "ser consideradas manifestações das estruturas metafísicas ou ontológicas do espírito, sendo o espírito translucidez da presença a si mesmo ou consciência-de-si” (VAZ, 2006, p. 220). Para Vaz (2006, p. 222), “o ato espiritual é, assim, o ato vital por excelência, e é nele que a vida emerge definitivamente sobre suas formas biopsíquicas, mostrando-se como perfeição simples ou transcendental, e encontra no Espírito infinito sua realização absoluta"; torna os seres humanos, plenamente humanos em relação com o outro:

Tal é o paradoxo do espírito finito: riqueza e plenitude com relação ao mundo exterior que ele compreende pelo saber, transfigura pela arte, transforma pela técnica; pobreza e carência com relação ao outro que ele encontra no reconhecimento e no amor e, de modo radical, com relação ao Outro absoluto do qual espera a palavra última sobre sua origem e sobre seu destino (VAZ, 2006, p. 222).

Assim, para muito além da perversa redução do ser humano ao aspecto corporal ou biológico, o esforço de Vaz é reconstruir uma fundamentação ontológica do ser. Para Vaz (1992, p. 34), a ideia do "Eu sou" envolve reflexões sobre o ser-no-mundo enquanto questiona a amplitude transcendental desse "Eu sou", ou seja, "a realidade do ser do homem na sua relação com a realidade exterior que o envolve (ser-no-mundo), iguala-se à amplitude transcendental da afirmação Eu sou?" E, esse “ser-no-mundo, exprimindo-se, na verdade, como ser-para-o-mundo (relação ativa), deve ser integrado no dinamismo totalizante 
do discurso da Antropologia Filosófica" (VAZ, 1992, p. 35). É nessa trama que o sistema antropológico filosófico vaziano se constitui no "relacionar-se com o outro (relação de alteridade)"’ (VAZ, 1992, p. 12).

Todo o esforço de Vaz foca na reflexão sobre o ser humano como tentativa de superar a fragmentação reducionista e chama a atenção para sua dimensão espiritual, pois "é vivendo segundo o espírito que o homem vive humanamente a vida corporal e a vida psíquica. Todos os saberes normativos sobre a vida humana (a Religião, a Ética, a Política...) pressupõem essa primazia determinante do espírito na definição da vida humana enquanto humana" (VAZ, 2006, p. 218).

A redução do ser humano à dimensão biológica exige prudência, pois já os gregos usavam dois termos diferentes para se referirem à vida, como escreve Agamben (2010, p. 9): zoé que "exprimia o simples fato de viver comum a todos os seres vivos (animais, homens ou deuses) e bíos [...] a maneira de viver, própria de um indivíduo ou de um grupo". É importante reconhecer que, como assevera Agamben (2010, p. 9), Platão no Filebo faz referência a três gêneros de vida e "Aristóteles, na Ethica nicomachea, distingue a vida contemplativa do filósofo (bíos theoreticós) da vida de prazer (bíos apolausticós) e da vida política (bíos políticos)". Significa, segundo Agamben (2010), que nem Platão e nem Aristóteles se referiam somente à vida natural, a simples zoé, "mas uma vida qualificada [...] vida mais nobre e eterna" (p. 9). Essa tradição grega persiste marcando presença na cultura ocidental, manifesta pela vida do espírito, reafirmada por Vaz, como forma de qualificar os modos de vida das pessoas, por meio da intersubjetividade, que, para Hegel (2005, p. 118), é a condição à vida no espírito.

[....] a subjetividade implica o que é diferente de si e o poder de se opor e tratar o diferente como algo de negativo. É a negatividade infinita, a negação, e a natureza representa esta última. Tal idealidade e tal negatividade infinita

7 Para Oliveira (2011, p. 22), "uma ação do sujeito racional e livre na sua relação de reconhecimento e de consenso com o outro [...] possui como norma o horizonte universal do Bem. Assim pode ser definida a ação ética intersubjetiva na ética filosófica de Vaz: [...] O outro com o qual eu me relaciono não é um objeto ao meu dispor. Como sujeito racional e livre, ele deve ser reconhecido na sua dignidade de fim em si”. 
formam o conceito profundo da subjetividade do espírito. Mas enquanto subjetividade, o espírito ainda não é mais do que verdade da natureza, visto que ainda não formou o conceito de si para si.

As argumentações de Hegel sobre subjetividade revelam a essência e os limites da subjetividade evidenciando que a consciência subjetiva, de forma autorreferenciada, não é capaz de desenvolver a consciência de si para si, uma vez que está impossibilitada de reconhecer-se como interdependente, como intersubjetiva. "Enquanto a liberdade permanece subjetiva, sem se exteriorizar, o sujeito acha-se em presença do que não é livre, do que só é objetividade e necessidade natural" (HEGEL, 2005, p. 32). Tais argumentos indicam que a emergência da dimensão espiritual como consciência verdadeira e "mais elevada", só se efetiva na alteridade, quando essa intersubjetividade possibilita a consciência de si para si desabsolutizando a subjetividade.

\section{Intersubjetividade e a Paideia do Educar}

$\mathrm{Na}$ tradição ocidental as reflexões sobre vida e ser humano têm como referência uma educação capaz de produzir experiências formativas do conhecer-se e encontrar no espírito humano as melhores formas de existência humana, como afirma Jaeger (2010, p. 3):

Uma educação consciente pode até mudar a natureza física do homem e suas qualidades, elevando-lhe a capacidade a um nível superior. Mas o espírito humano conduz progressivamente à descoberta de si próprio e cria, pelo conhecimento do mundo exterior e interior, formas melhores de existência humana.

A vivência dessa educação, capaz de oportunizar a todos os humanos um conhecimento de si mesmo e melhorar seu modo de ser na existência, exige a percepção de que, somente a partir do outro, me qualifico como um 
humano melhor. É um imaginário a ser disseminado nas salas de aula para permitir aos estudantes condições de liberdade, preferencialmente voltadas para o bem viver. ${ }^{8}$

Para Vaz, a essência do ser pessoa (persona), tornada possível pela educação, envolve visão de unidade, conhecimento da verdade e realização do bem, mas não sem a constelação transcendental. Nesse sentido escreve:

Como o Ser, seja na sua infinitude intencional seja na sua infinitude real, se desdobra em Unidade, Verdade e Bem, a pessoa é, por sua própria natureza, o sujeito dos atos que são correlatos à constelação transcendental do Ser e dos seus atributos: toda visão de Unidade, todo conhecimento da Verdade, todo consentimento ao Bem são atos da pessoa, e só como atos empenhativamente pessoais operam no homem a síntese da essência e da existência, do que ele é e do que deve ser (VAZ, 1992, p. 193).

A constituição do ser como pessoa, a partir da formação do ethos na tradição ocidental, exige, como consequência ontológica, a desestruturação da compreensão de ser humano sustentada pela vertente iluminista, mas na contraposição com esta. A necessidade dessa desestruturação fica evidenciada diante da onda niilista, do hedonismo e dos relativismos que tomam conta da contemporaneidade, centrados no cuidado a si mesmo, nas falácias e promessas de felicidade, na desconfiança e corrupção disseminadas. A contemporaneidade, todavia, também produz os resistentes a essas "doenças contemporâneas"; resistentes que apostam no uso da educação como um dos remédios para curar o mal-estar do século 21. Apostam numa maior amizade entre filosofia e educação, pois, como anuncia Agamben (2009, p. 79), "amizade e filosofia é tão profunda que esta inclui o philos, o amigo, no seu próprio nome".

Essa educação, aberta para a intersubjetividade, reconhece, segundo Agamben (2009, p. 89), que "a amizade é a instância desse com-sentimento da existência do amigo no sentimento da existência própria. Mas, isso significa

\footnotetext{
8 “[...] o agir ético não é uma ação do sujeito isolado, mas sim do sujeito numa relação de reconhecimento e consenso com o outro orientado pela norma do bem viver e do bem agir. Ao afirmar a ação moral como uma ação do indivíduo, cumprida no seio de uma comunidade histórica e orientada pela normatividade do ethos, Vaz pensa o ser humano na sua unidade num processo de autorealização" (OLIVEIRA, 2011, p. 24).
} 
que a amizade tem um estatuto ontológico e, ao mesmo tempo, político". Esse sentido de amizade, como um dos caminhos para a consolidação da construção do ser pessoa, poderia, conforme Agamben (2009, p. 87), "criar uma existência que seja desejável porque se sente que esta é uma coisa boa e essa sensação (aisthesis) é em si doce".

A educação, criadora dessa disposição pela amizade, configura-se como reflexão sobre o outro amigo na intersubjetividade. Agamben (2009, p. 90) afirma que "o amigo não é um outro eu, mas uma alteridade imanente na 'mesmidade', um tornar-se outro do mesmo", contribuindo na construção de existência social mais doce. Essa educação será terreno fértil da ética na corresponsabilidade pelo outro, como amigo, por repartir a existência. Novamente a amizade como "a condivisão que precede toda divisão, porque aquilo que há para repartir é o próprio fato de existir, a própria vida". Uma amizade na corresponsabilidade relacionada com a "partilha sem objeto, esse com-sentir originário que constitui a política" (AGAMBEN, 2009, p. 92). Esse com-sentir, anunciado por Agamben, transformado em Paidéia ética, reacende a intersubjetividade relacional com o outro e com o meio ambiente. Educar para uma Paidéia ética pressupõe trilhar em um caminho do reconhecimento ou, como asseveram Maturana e Yáñez (2009), o “caminho do amar", posto que, como expressa Bauman (2004, p. 98), "aceitar o preceito do amor ao próximo é ato de origem da humanidade". Ele ainda salienta que, "com esse ingrediente, a sobrevivência de um ser humano se torna a sobrevivência da humanidade no humano". Numa Paideia Ética, a educação oportuniza, aos educandos, a escolha do Bem, compreendido como amar, que "é visionário, pois ocorre na ampliação do ver (do ouvir, do sentir, do cheirar, do tocar) próprio do espaço das condutas relacionais que ocorrem sem preconceitos, sem expectativas, sem generosidade, sem ambição" (MATURANA; YÁÑEZ, 2009, p. 84). Desse modo, “conviver fora do amar não é conviver social" e, mais que isso, "sem o bem-estar do outro e de si mesmo na convivência não é possível viver no caminho do Amar" (MATURANA; YÁÑEZ, 2009, p. 85) por inviabilizar a construção de uma Paidéia ética. 
Ora, esse reconhecimento pressupõe a necessidade de conhecer-se, reconhecer-se para melhor viver com o outro, saber amá-lo, sem sufocá-lo, sem matá-lo, sendo um sábio/louco na arte de amar, mas um conhecer-se que não é possível no ensimesmar. Karl Jasper (1965, p. 125) argumenta: “esse amor de que falamos como se soubéssemos o que ele seja, esse amor único e abrangente é aquele em que somos autenticamente o que somos". Como seres em construção estamos em constante processo de formação, vivenciando relações mais intensas e autênticas com e como outro.

Para Vaz (1992, p. 223), esse amar como "com-sentir" (AGAMBEN, 2009) e como "bem-estar do outro e de si mesmo na convivência" (MATURANA; YÁÑEZ, 2009), fundamenta a liberdade, considerando que "A vida do espírito enquanto inteligência tem, pois, como sua operação suprema, a contemplação (noésis ou theoría), ou seja, o acolhimento do ser; e, enquanto liberdade tem, como sua operação suprema, o amor desinteressado (Agápe), ou seja, o dom ao ser".

Vaz (2006, p. 3), ao perguntar-se “o que é o ser humano?”, afirmava que o mesmo corresponde a uma eterna busca do conhecer-se, do perceber-se em construção e bem-estar do outro, como na amizade e no amar. Trata-se, segundo Vaz, de uma busca incessante pela função social, acreditando na educabilidade humana e no reconhecimento do outro então como amigo. Chardin (1988, p. 278) argumenta que essa humanidade, concebida no reconhecimento, "em seu obscuro sentido de crescimento permanente se aliava a uma necessidade de fraternidade universal. Humanidade: objeto de uma fé muitas vezes ingênua [...] continua a atuar com a mesma força de sedução".

O reconhecimento do outro, na perspectiva vaziana, significa admitir que o ser humano possui uma infinitude intencional diante da infinitude intencional do outro e, nesse processo dialético, se estabelece a relação de intersubjetividade na linguagem. Vaz (1992, p. 50) informa:

O aparecimento do outro no horizonte da intencionalidade do Eu tem lugar, por conseguinte, no medium da linguagem entendida no seu sentido mais amplo como estrutura significante que se diferencia em múltiplas formas, desde a postura corporal e o gesto até a prolação e a articulação do discurso, em particular do discurso da interlocução (diá-logos). 
Nessa interlocução com a alteridade reside uma possibilidade de construir um processo educativo, tendo como premissa a estrutura psíquica da relação com o outro formalizada no terreno da linguagem e na relação de diálogo: "a relação dual EU-TU constitui o círculo originário do Nós" (VAZ, 1992, p. 51). Essa relação dialógica entre os seres humanos traz à tona a noção de intersubjetividade como possibilidade de relação diante das transformações históricas do ethos moderno para o contemporâneo. Uma transformação cultural que provoca, na comunidade humana, o desapego pelo bem do outro, posto que, prioritariamente, toda a organização humana encontra centralidade no consumismo, na gestão de si mesmo e na busca pelo poder. Segundo Sampaio (2001, p. 120), essa lógica de despreocupação em relação ao outro explica "a submissão da esfera do político aos critérios da eficácia, da utilidade, do lucrativo, que visam solucionar, única e exclusivamente, as questões relativas à associação e à satisfação das necessidades básicas e vitais", prioritariamente, em dimensões singulares.

Essa nova dimensão social voltada exclusivamente aos critérios mercadológicos de uma sociedade do lucro, segundo a perspectiva vaziana, foi sendo forjada juntamente com os avanços das ciências e do desenvolvimento da técnica, causando rupturas ontológicas na relação com o outro. Ela acaba, todavia, também sendo um convite que:

Consiste em fazer surgir o problema do outro no âmbito da dialética do reconhecimento, ao termo das experiências que a consciência faz no seu relacionar-se com o mundo objetivo e que conduzem, através de um complexo movimento dialético, ao aparecimento da noção de infinito, suscitando o descobrir-se interno da consciência, agora assumindo a figura da consciência-de-si (VAZ, 1992, p. 54).

Então, grande parte do problema está na consciência que não mais reconhece o outro. Na perspectiva vaziana, porém, é necessário encontrar na consciência-de-si o caminho para o reconhecimento no "relacionar-se com outro sujeito o qual, por sua vez, é igualmente ele mesmo (ipse) no seu ser-conhecido e no conhecer seu outro: em suma, no reconhecimento" (VAZ, 1992, p. 55). É nesse sentido que: 
A reciprocidade constitutiva da relação com o outro mostra, assim, a impossibilidade do solipsismo (solus ipse). Essa impossibilidade se demonstra exatamente em virtude do movimento dialético pelo qual a relação de objetividade é suprassumida na relação intersubjetiva. A suprassunção significa aqui que a forma do ser-no-mundo como auto-expressão do sujeito implica necesariamente a forma do ser-com-o-outro que é, justamente, a forma da relação intersubjetiva (VAZ, 1992, p. 55).

Para Vaz (1992), na pré-compreensão (a construção das formas simbólicas e manifestações religiosas), que tornou possível a existência do ser humano, se encontram fragilidades e ausências para o exercício autêntico da relação com a alteridade, como intersubjetividade e, por conseguinte, efetivação de uma educação humanizadora. A saída de Vaz, diante desses impasses históricos, é fundamentar a reflexão sobre o outro a partir das concepções da fenomenologia, da gnosiologia, da psicologia, da lógica, da ética e da história. Segue uma rápida entrada para enfatizar, distintivamente, a abrangência de cada contribuição.

A educação humanizadora alimenta-se dessas fontes para efetivar o sonho do reconhecimento do outro. A perspectiva fenomenológica, como "dialética entre sujeitos" inicia, segundo Vaz (1992, p. 56), nas reflexões de Husserl: "para estabelecer a realidade do outro no âmbito da esfera intencional do Eu e dentro do problema geral da constituição da realidade enquanto medida e regida pelo Eu transcendental, problema que oferece a linha diretriz das Meditações Cartesianas".

A gnosiologia pressupõe que o conhecimento acerca do outro, com a finalidade do reconhecimento, se potencializa nos encontros realizados de forma cada vez mais profunda. Conforme Vaz (1992, p. 57), diferentemente de Husserl,

As laboriosas tentativas para fundamentar o conhecimento do outro ou para dar-lhe um estatuto gnosiológico adequado repousam sempre, e definitivamente, sobre a realidade primeira do encontro, que se desenrola em formas sempre mais profundas a partir da relação fundamental do reconhecimento.

A reflexão psicológica serve de referência, pois, para ela, a relação intersubjetiva com o outro "formula-se no plano da realidade empírica do encontro com o outro, na medida em que ele se efetiva através da vida psíquica, desde 
a simples percepção à imaginação e à afetividade" (VAZ, 1992, p. 57). Na interpretação de Sampaio (2001, p. 127), “o psiquismo tem função privilegiada na relação de intersubjetividade, pois a essencial reciprocidade deve ser vivida subjetivamente".

O aspecto lógico resulta da relação intersubjetiva "ligado ao médium da linguagem em que essa relação se estabelece, uma vez que toda lógica é linguagem e todo uso da linguagem implica uma lógica" tornada possível no diálogo (VAZ, 1992, p. 58).

As reflexões no universo da ética são fontes de referência, pois, para Vaz, somente uma profunda compreensão do existir-com-o-outro torna possível a existência na relação intersubjetiva. Vaz (1992, p. 59) discorre que: "com efeito, esse co-existir se mostra constitutivamente como um co-existir no espaço do ethos, ou no seio da comunidade ética". A proposição de Vaz encontra sustento na vida ética como essência do existir-em-comum na Arete grega, ou seja:

O questionamento dialógico com que Sócrates introduz na filosofia o tema da intersubjetividade tem em vista, em primeiro lugar, a vida ética ou o exercício da Arete, noção essencialmente voltada, na sua acepção grega original, para o reconhecimento no seio do existir-em-comum (VAZ, 1992, p. 59).

Quanto ao aspecto histórico, Vaz o propõe considerando que toda relação intersubjetiva é essencialmente histórica, por se constituir no existir-em-comum dos seres humanos. Para ele,

\begin{abstract}
A história aqui é [...] o modo próprio com que a comunidade humana existe no tempo e que encontra sua efetivação nos costumes, nas instituições, na linguagem, na sensibilidade comum, em suma nos diversos aspectos da relação de intersubjetividade que definem para os indivíduos e para os grupos a forma do seu existir histórico (1992, p. 59).
\end{abstract}

A partir dessa complexa estrutura conceitual para a compreensão vaziana, "o mundo histórico-social é, portanto, o mundo das iniciativas e obras humanas - o mundo do nós ou da cultura". O ser humano é ser-no-mundo, na categoria da objetividade, contudo torna-se ser-com-o-outro na categoria da intersubjeti- 
vidade (VAZ, 1992, p. 60). Essa reciprocidade intersubjetiva propicia aos seres humanos a ressignificação para a proximidade, a convivência e a permanência, como sustenta Vaz (1992, p. 60):

A relação recíproca da proximidade, que se exerce como relação Eu-Tu no amor, na amizade, na vida em comum; a relação recíproca da convivência, que se exerce como relação Eu-Nós no consenso, na obrigação, na fidelidade; a relação recíproca da permanência, que se exerce como relação Eu-outros na tradição, no costume, na vida social e política.

$\mathrm{Na}$ argumentação de Vaz destaca-se a importância do outro no processo de construção do próprio ethos para uma existência comunitária. Essa profunda compreensão da intersubjetividade tem seu berço entre os gregos ao proporem que "a única forma de vida em comum digna deste nome era a koinomía politiké, que os latinos traduziram por societas civilis e que era, justamente, objeto de um saber normativo, a episthéme politiké, que Aristóteles define como o "supremo ordenador entre os saberes" (VAZ, 1992, p. 61). Para Vaz (1992, p. 62), na "relação de intersubjetividade, sendo essencialmente comunhão ou encontro que tem lugar na reciprocidade dos atos espirituais (reconhecimento e liberdade) ou sendo presença", se encontra a força para a não submissão às mazelas contemporâneas, como da política corrupta, do consumismo exacerbado, do individualismo doentio e da constante busca pelo poder.

\section{Intersubjetividade como Agápe $^{9}$ na Educação}

A agápe, na educação, subsidia a compreensão da humanização a partir da intersubjetividade; lá "o sujeito tem diante de si um outro sujeito e deve assumi-lo no discurso da auto-afirmação de si mesmo: vale dizer, tem diante de si uma outra infinidade intencional" (VAZ, 1992, p. 65). Essa intersubjetividade,

9 Retomamos aqui a referência de Vaz (1992) (Agápe) como o amor desinteressado, o dom ao ser. 
para Vaz, significa um encontro espiritual no reconhecimento do outro como "identidade dialética do Eu com o não-Eu como Eu (alter ego)" (VAZ, 1992, p. 65). Significa proposição de acolhida do outro e sua não coisificação.

Vaz sustenta essas reflexões em duas vertentes filosóficas, constituintes da tradição ocidental, sobre relações intersubjetivas: a aporética histórica e a aporética crítica. Na aporética histórica o problema da comunidade humana, de intersubjetividade, tornou-se tema de reflexões filosóficas. No outro, inserido na comunidade histórica, "o homem pode participar: família, cidade, confrarias religiosas ou filosóficas e, finalmente, a comunidade do gênero humano" (VAZ, 1992, p. 68).

Na Antiguidade a aporética histórica vincula intersubjetividade com "o fio da 'natureza' (physis) que se manifesta na disposição natural, na afinidade, na afetividade; e o fio da 'razão' (logos) que se manifesta no ideal do bem e da virtude como fim da amizade" (VAZ, 1992, p. 68).

No período medieval a constituição histórica das relações intersubjetivas alinhava-se com o antigo testamento pela "revelação do próximo (o pleisíon)" e, no novo testamento na "revelação da agápe do amor-dom de Deus (charitas, caridade)" (VAZ, 1992, p. 68). Na Modernidade, segundo Vaz (1992, p. 69), encontra-se "a ocultação do outro no racionalismo moderno. A revolução copernicana iniciada por Descartes é levada a cabo por Kant ao afirmar a famosa frase: 'Eu penso'”.

Em relação ao período moderno Vaz se questiona: Como justificar, a partir do Eu, a pluralidade dos sujeitos? Inúmeras foram as tentativas filosóficas visando a repensar a supremacia do $\mathrm{Eu}$, tais como o racionalismo, o empirismo e o criticismo.

Para Vaz, esse Eu precisa ser compreendido nos termos hegelianos, ou seja, uma dialética do reconhecimento que acena para as dificuldades de vivência na comunidade histórica, pois "a solidão a-histórica do Eu cede lugar à emergência do Nós e aos passos da sua constituição como sujeito histórico: a luta, o reconhecimento, a cultura" (VAZ, 1992, p. 70) e nela, quem sabe, a possibilidade da vivência humanizadora. 
A compreensão histórica da relação intersubjetiva, na contemporaneidade, passa por discussões, conforme Vaz, fundamentadas na fenomenologia, na lógica e na linguagem. Vaz alerta que a "definição de uma autêntica comunidade universal de comunicação exige uma reflexão filosófica aprofundada sobre a relação do reconhecimento, sem a qual a comunicação se instrumentaliza e, finalmente se desumaniza" (VAZ, 1992, p. 71). No contexto instável da contemporaneidade, quanto à dignidade humana, Vaz (1992, p. 71) questiona:

Considerada a relação dual ou plural entre os sujeitos, qual o fundamento que permite a essa relação transcender de alguma maneira o seu natural e histórico para constituir-se como relação que revela no outro a presença de uma dimensão axiológica fundamental: a dignidade em um outro EU?

Para pensar a dignidade num outro Eu, como fundamental na intersubjetividade, constituída como reconhecimento, Vaz baseou sua reflexão na aporética crítica. A provocação para essa reflexão, segundo a interpretação de Sampaio (2001, p. 135) se encontra na importância da passagem "do nós empírico ao nós inteligível, na medida em que o problema se constitui no desafio de manutenção da unidade inteligível do eu na comunidade do nós". Diante dessa interpretação, encontramos no próprio pensamento de Vaz a formulação da questão central:

Como manter a unidade do eu na comunidade do nós, ou ainda, como preservar a originalidade do sujeito individual ao ser ele suprassumido na unidade de um sujeito transindividual que é, ao mesmo tempo, plural nos sujeitos concretos nos quais se realiza o uno pela relação intersubjetiva que se estabelece entre eles? (1992, p. 72).

Na compreensão vaziana, a intersubjetividade torna-se possível graças ao ser-no-mundo como estrutura relacional com o outro sendo ser-com-o-outro. Vaz reafirma a ideia de "horizonte do ser. O mundo é, para cada um de nós, o caminho para o encontro do outro" (1992, p. 74). Assim, o momento eidético da compreensão filosófica da intersubjetividade é constituído pela aporética histórica e a aporética crítica. Segundo Vaz (1992, p. 74), essa relação do eidos com a intersubjetividade compreende-se a partir do "espaço conceptual 
delimitado pela pluralidade dos sujeitos e pela relação que estabelece entre a forma de uma unidade na pluralidade". A consecução desse propósito de que "O Eu é um Nós" é possível no movimento dialético, pois

[...] a relação de intersubjetividade, desdobra-se desde o nível da relação Eu-Tu no encontro, atinge a amplitude da relação Eu-Humanidade na longa dimensão do tempo e do espaço onde se desenrola a História [...] pessoal ligada por mil fios - os fios do universo cultural. É sabido que esse nível mais abrangente da relação de intersubjetividade, seja na sua incidência subjetiva como consciência histórica, seja na sua face objetiva como sentido da História, passou a ser um lugar privilegiado da reflexão sobre o homem no pensamento filosófico, de Hegel a nossos dias (VAZ, 1992, p. 79).

$\mathrm{Na}$ contemporaneidade, contudo, se vive, fragilmente, a proposição de um Eu como Nós, ou seja, estamos ainda distantes da superação das ideologias dominantes, dos individualismos e dos totalitarismos. Diante dessa fragilidade, Vaz afirma ser necessário introduzir "o princípio da ilimitação tética", como possibilidade de negar o imaginário do "Eu não é um Nós" e constituir a "identidade na diferença como dialética da alteridade" (VAZ, 1992, p. 76). Com essa ênfase na comunidade compreende-se, filosoficamente, ser possível formular uma educação humanizadora baseada no reconhecimento do outro, uma relação Eu-Tu. Trata-se, de acordo com Vaz (1992, p. 236), de "uma construção coletiva e, como tal, demanda esforço, tempo, retrocesso, diálogo, negociação", ou seja, "trata-se de aprender a viver juntos, de educar-se para a reciprocidade e para uma vivência ética não apenas humana, mas que perpasse relações éticas com todos os seres vivos do planeta. Precisamos nos re-educar". É, uma possibilidade atual de refletir sobre: O que é o Ser Humano? Reflexão ensaiada por Vaz (1992, p. 236) como o "reconhecimento de uma presença atuante de uma Inteligência infinitamente bondosa e de um Amor infinitamente verdadeiro". Um necessário remergulho nos valores metafísicos, como fundamentais para a formação ontológica e para a perpetuação do ethos na comunidade humana humanizada. 


\section{Considerações Finais}

Os estudos de Vaz sobre a ontologia clássica encontram sustento no mundo antigo e medieval, influenciados pelos pensamentos de Aristóteles e Tomás de Aquino, para os quais o humano encontra a sua humanidade na polis e na comunidade. Na modernidade o pensamento de Vaz vem da dedicação aos estudos de Galileu, Descartes, Espinoza e, finalmente, Kant, questionando o "eu penso". Consolidado por um viés crítico e com preocupações acerca da ruptura da metafísica, na modernidade e, ao vertiginoso desenvolvimento científico-técnico com impactos profundos na cultura ocidental, passa a guiar-se pelo relativismo de valores e referencial de ação que passa a ser o hedonismo. Dessa forma, no viés histórico da crise da modernidade torna-se possível identificar uma Paidéia em decadência em razão da fragmentação dos valores éticos e políticos, de certa forma impostos pelo desenvolvimento do racionalismo da tecnociência. Essa crise expõe consequências ontológicas à vida humana com o surgimento de novos racionalismos, alienalismos e individualismos que inviabilizam a autorrealização dos seres humanos.

As reflexões sobre a cultura ocidental sinalizam para o desafio da construção de uma educação humanizadora, compreendida como Paidéia e embasada na ética. Essa educação humanizadora encontra referência numa melhor compreensão ontológica do ser humano e na esperança de não mais concebê-lo como ente fragmentado e morto de intersubjetividade, mas sim como ser humano constituído na e pela intersubjetividade plural. Assim, trata-se de repensar a educação como possibilidade de mudança nos modos de vida dos seres humanos reeducando-os para vivências que efetivem ações solidárias, políticas justas, sistemas econômicos priorizando o viver comunitário e não o fortalecimento de individualismos. Reafirma-se a concepção de educação como caminho de humanização nas relações com o Outro, e é nesse momento que o pensamento de Vaz torna-se promissor, na medida em que contribui para a reabilitação do espírito como condição humana, possível pela linguagem que articula o soma e o psiquismo como fonte de relações intersubjetivas. Por isso, o pensamento de Vaz constitui-se uma importante base de diálogo na busca de elementos que subsidiem respostas tanto ao problema do dogmatismo quanto ao do relativismo. 
Guiado pela intersubjetividade, compreende e projeta a educação pautada pela ética, cujos fins precisam ser redefinidos em meio aos desafios dos relativismos e da pluralidade de valores no contraponto à tradição. A isso Vaz dedicou sua existência, embora não tenha produzido reflexões específicas sobre a educação.

Mesmo assim, suas reflexões, como destacamos no texto, permitem transposições como processos educativos. Desse modo, uma educação voltada para o reconhecimento é, acima de tudo, um desafio por vivências éticas tendo como base a intersubjetividade como experiência em comunidade; uma vivência ética desatrelada do cumprimento de normativos, sem filiação a essências humanas, mas sonhando, concretamente, a possibilidades de vivenciar a liberdade.

Assim, podemos afirmar, nos termos de Agamben, que Vaz é um filósofo contemporâneo no rigor do termo. Sua grande virtude está em reabilitar e evidenciar a atualidade da comunidade como importante condição ao ser humano em meio ao crescente individualismo. Não é um pensador isento, contudo, de questionamentos, mas porque questionador e questionável é produtivo, na medida em que a radicalidade de seu pensamento evidencia os desmandos modernos e ditos pós-modernos.

\section{Referências}

AGAMBEN, Giorgio. O que é o contemporâneo? E outros ensaios. Chapecó, SC: Argos, 2009.

Homo Sacer: o poder soberano e a vida nua I. 2. ed. Belo Horizonte: UFMG, 2010.

BAUMAN, Zygmunt. Amor líquido: sobre a fragilidade dos laços humanos. Rio de Janeiro: Jorge Zahar, 2004.

CHARDIN, Pierre Teilhard de. Ofenômeno humano. São Paulo: Martin Claret Editores, 1988.

HEGEL, Georg Wilhelm Friedrich. Estética. São Paulo: Nova Cultural, 2005. (Os Pensadores).

JAEGER, Werner. Paidéia: a formação do homem grego. 5. ed. São Paulo: Martins Fontes, 2010. 
JASPER, Karl. Introdução ao pensamento filosófico. 3. ed. São Paulo: Cultrix, 1965. MATURANA, Humberto; YÁÑEZ, Ximena Dávila. Habitar humano em seis ensaios de biologia-cultural. São Paulo: Palas Athenas, 2009.

MORIN, Edgar. O método 6: ética. Porto Alegre: Sulina, 2005.

MONOD, Jacques. O acaso e a necessidade. Portugal: Publicações Europa-America, 2002.

OLIVEIRA, Cláudia Maria Rocha de. Uma ética para além do relativismo e da fragmentação. In: IHU online (Instituto Humanitas Unisinos), São Leopodo: Unisinos, edição 374 , p. 22/26, 26/9/2011.

RATZINGER, Joseph. As bases pré-políticas e morais do Estado democrático. 2004. Disponível em: <http://www1.folha.uol.com.br/fsp/mais/fs2404200506.htm>. Acesso em: abr. 2010.

REPA, Luiz Sérgio. O senhor e o escravo: o desejo e a formação do sujeito em Hegel. In: Viver Mente \& Cérebro Especial, São Paulo, v. 3, p. 92-98, 2007.

RIBEIRO, Elton Vitoriano. A dimensão comunitária de Lima Vaz, Taylor e MacIntyre. In: IHU online (Instituto Humanitas Unisinos), São Leopodo: Unisinos, edição 374, p. 36/41, 26/9/2011.

SAMPAIO, Rubens Godoy. O ser e os outros: um estudo de teoria da intersubjetividade. São Paulo: Unimarco, 2001.

Metafísica e modernidade: método e estrutura, temas e sistemas em Henrique Cláudio de Lima Vaz. São Paulo: Loyola, 2006.

. Um sistema em resposta ao niilismo ético. In: IHU online (Instituto Humanitas Unisinos), São Leopodo: Unisinos, edição 374, p. 14/18, 26/9/2011.

SHATTUCK, Roger. Conhecimento proibido: de Prometeu à pornografia. São Paulo: Companhia das Letras, 1998.

VAZ, Henrique Claudio de Lima. Antropologia filosófica II. São Paulo: Loyola, 1992. . Morte e vida da filosofia. In: Síntese Nova Fase, São Paulo, v. 18, n. 55, p. 667-691, 1991.

. Ética e cultura. 4. ed. São Paulo: Loyola, 2004. . Antropologia filosófica I. São Paulo: Loyola, 2006. 